\title{
Gestão da Cadeia de Suprimentos Sustentável: uma Análise de uma Indústria Madeireira
}

\author{
Andreia Aparecida Pandolfi dos Santos \\ Universidade do Sul de Santa Catarina (Unisul) - Brasil \\ andripandolfi@yahoo.com.br \\ Andreas Wolter \\ Universidade do Sul de Santa Catarina (Unisul) - Brasil \\ andreasmarkuswolter@gmail.com \\ Simone Sehnem \\ Universidade do Sul de Santa Catarina (Unisul) - Brasil \\ simonesehnem_adm@yahoo.com.br \\ Camila Gomes \\ Universidade do Sul de Santa Catarina (Unisul) - Brasil \\ camila2527@gmail.com

\section{Gleberson Santana} \\ Senac - Brasil \\ glebersonsantana@hotmail.com
}

\section{Resumo}

Este trabalho teve como objetivo analisar o papel que as operações da cadeia de suprimentos sustentável desempenham nas organizações numa perspectiva que direcione para a circularidade de recursos. Consiste em estudo caso único, desenvolvido junto a uma indústria madeireira, de médio porte, localizada no sul do Brasil. Caracteriza-se como um estudo com abordagem qualitativa cujo enfoque é descritivo. Foi constatado que o papel que as operações industriais desempenham no contexto das cadeias de suprimentos sustentáveis é essencial e relevante. Suas operações são responsáveis pela geração de poluentes e resíduos. Esses passivos são tratados de maneira que minimizem o passivo ambiental que a empresa gera. Por intermédio da circulação de todos os resíduos dentro da cadeia produtiva ou aproveitamento por outros agentes se procura mitigar os impactos ambientais e aumentar a eficiência dos recursos naturais e a otimização dos materiais. A organização apresentou um importante papel no pilar ambiental, via engajamento de múltiplos stakeholders por meio de cumprimento de requisitos legais ambientais e a conscientização em prol da sustentabilidade ambiental. Nas diretrizes social relacionadas a normas e leis 
trabalhista dos direitos humanos, manuseios e treinamentos de operações de agentes tóxicos e máquinas, há engajamento também. Portanto, a organização age seguindo as diretrizes legais, impulsionadas não somente por órgãos governamentais, mas principalmente instigada pelos clientes atuais e potenciais.

Palavras-chave: cadeia de suprimentos, sustentabilidade, relações inter-organizacionais, economia circular 


\title{
Sustainable Supply Chain Management: An Analysis of a Timber Industry
}

\author{
Andreia Aparecida Pandolfi dos Santos \\ Universidade do Sul de Santa Catarina (Unisul) - Brasil \\ andripandolfi@yahoo.com.br \\ Andreas Wolter \\ Universidade do Sul de Santa Catarina (Unisul) - Brasil \\ andreasmarkuswolter@gmail.com \\ Simone Sehnem \\ Universidade do Sul de Santa Catarina (Unisul) - Brasil \\ simonesehnem_adm@yahoo.com.br \\ Camila Gomes \\ Universidade do Sul de Santa Catarina (Unisul) - Brasil \\ camila2527@gmail.com

\section{Gleberson Santana} \\ Senac - Brasil \\ glebersonsantana@hotmail.com
}

\begin{abstract}
This paper aimed to analyze the role that sustainable supply chain operations play in commercial responses to sustainability imperatives. This is a unique case study, developed together with a medium-sized timber industry, located in southern Brazil. This is a qualitative study whose approach is descriptive. It has been found that the role that industrial operations play in the context of sustainable supply chains is essential and relevant. Its operations are responsible for the generation of pollutants and waste is treated in a way that minimizes the environmental liability that the company generates, through the circulation of all waste within the production chain, used by other agents. The organization played an important role in the environmental pillar through multi-stakeholder engagement through compliance with environmental legal requirements and awareness of environmental sustainability. In social guidelines related to norms and labor laws of human rights, handling and training operations of toxic agents and machinery, there is also engagement. Therefore, the organization acts following legal guidelines, driven not only by government agencies, but mainly instigated by current and potential clients.
\end{abstract}


Keywords: supply chain, sustainability, inter-organizational relations, circular economy 
Os tradicionais modelos de produção industriais contribuem significativamente com a aceleração das mudanças climáticas. Provocavam o desmatamento, a queima de combustíveis fósseis e a agricultura intensiva. A partir desta perspectiva, líderes empresariais, consumidores e governo tem descoberto que a continuidade da geração de riqueza exige um novo modelo industrial que é menos dependente da energia primária e de insumos primários e é capaz de regenerar o capital natural (World Economic Forum, 2014).

Para uma cadeia de suprimentos ser considerada sustentável, precisa obter um bom desempenho em medidas financeiras tradicionais, incluindo também as dimensões social e ambiental em suas medidas estratégicas (Pagell \& Wu, 2009).E Green Supply Chain Management (GSCM) é uma abordagem moderna de gestão ambiental e tem como pressuposto que as empresas não agem sozinhas, mas se interligando desde fornecedores iniciais até os consumidores finais, formando as chamadas cadeias de suprimentos, que estão preocupadas em atender as exigências do mercado com a adoção de princípios de gestão ambiental (Jabbour et al., 2013).

Se tratando de sustentabilidade na cadeia de suprimentos essa pode ser formada por três dimensões: social, ambiental e econômica (Carter \& Rogers, 2008). A dimensão ambiental, subentende que o modelo de produção e consumo deve ser compatível com a base material em que a economia se apóia; a dimensão econômica, supõe o aumento da eficiência da produção e do consumo com economia crescente de recursos naturais; e a dimensão social, prevê que todos os cidadãos tenham o mínimo necessário para uma vida digna, e que ninguém absorva bens, recursos naturais e energéticos que sejam prejudiciais a outros (Nascimento, 2012).

Baseado neste contexto, a questão norteadora da pesquisa consiste em: Qual é o papel que as operações da cadeia de suprimentos sustentável podem desempenhar nas organizações numa perspectiva que direcione para a circularidade de recursos?

O objetivo geral deste artigo é analisar o papel que as operações da cadeia de suprimentos sustentável desempenham nas organizações numa perspectiva que direcione para a circularidade de recursos.Para que o objetivo geral seja alcançado, são propostos os seguintes objetivos específicos: a) Identificar os papéis que as operações industriais desempenham no contexto da cadeia de suprimentos sustentável; b)Mapear os papéis que a organização pesquisada desempenha enquanto indústria processadora e nas suas relações inter-organizacionais com os fornecedores e com os clientes dentro da cadeia de fornecimento; c)Mapear os papéis desempenhados pelo ambiente institucional (governos, 
sindicatos, entidades representativas dos setores industriais e consumidores) sobre a responsabilidade compartilhada de produtos, a implementação de sistemas de logística reversa e a gestão de resíduos envolvendo as cidades, as empresas, distribuidoras e importadoras; d)Propor um plano estratégico de implantação de ações que contribuam para a obtenção de uma cadeia de suprimentos sustentável na organização pesquisada.

Com base no exposto, a lacuna que motiva a realização deste estudo está associada ao fato de ser uma temática pouco explorada no Brasil segundo Nascimento, Lemos \& Mello (2008) e o estudo de Oelze (2017), e principalmente por ser uma grande oportunidade para agregar valor ao produto, minimizar os impactos no processo de produção, gerar inovações de produto e processo e aumentar a competitividade da cadeia de suprimentos com a inserção sustentável. O GSCM colabora para a melhoria do desempenho, demanda capacitação de toda a cadeia de suprimentos, além de conduzir periódico, medições, programas de melhoria e redução de custos (Sehnem \& Oliveira, 2016).

\section{Fundamentação Teórica}

Os recursos podem ser divididos em duas diferentes classificações, isto é, em abundantes ou escassos. A forma como os utilizamos hoje, irá influenciar de maneira direta e indireta a forma em que os recursos deverão ser utilizados no futuro. Quanto maior o uso de matérias-primas e materiais reutilizáveis, maior será a disponibilidade de recursos considerados escassos para as gerações futuras. O modelo de Economia Circular (EC) surge exatamente com o propósito de agregar valor aos produtos por tanto tempo quanto for possível, minimizando impactos ambientais gerados por desperdícios e exploração predatória de recursos. Sendo assim, o modelo circular aplicado as indústrias, cria e proporciona um maior valor para cada recurso natural utilizado quando comparado com os modelos tradicionais lineares de produção (Di Maio et al, 2017).

A Economia Circular é definida como um sistema industrial que é restaurador ou regenerativo. Um sistema que serve com o intuito de repelir o conceito de fim de vida de um produto e o substitui por restauração. Que atua de forma sustentável a fim de eliminar o uso de produtos químicos tóxicos, que acabam por prejudicar a reutilização e o retorno à Biosfera, por meio de um design superior que atua e se desenvolve sobre uma compilação formada por materiais, produtos, sistemas e modelos comerciais (Ellen MacArthur Foundation, 2013).Transformar a economia industrial linear para uma economia circular é, 
por definição, reduzir a importância econômica da extração de recursos naturais e do gerenciamento de desperdícios e, por consequência, reduzir o impacto ambiental causado pelos setores industriais (Stahel, 2014).

São diversos os métodos que podem ser aplicados nas indústrias para que um modelo de economia circular se desenvolva da maneira mais efetiva a fim de minimizar os impactos ambientais e agregar maior valor a cadeia produtiva. Esses métodos podem ser monitorados em cinco etapas do processo produtivo circular, sendo assim, quando a última etapa é concluída, volta-se ao primeiro ponto. A primeira etapa é a adição de materiais e insumos para a produção, que é seguida do design aplicado ao produto, a produção e entrega do mesmo para o mercado, e por fim, o consumo e a avaliação do fim do ciclo de vida do produto elaborado(Elia, Gnoni \&Tornese, 2016).

Uma análise completa sobre uma economia circular aplicada à um processo industrial, pode-se abstrair de recentes estudos - como o relatório da Agência Ambiental Européia elaborado em 2016, cinco elementos que devem ser aplicados, e que quando medidos corretamente, atuam como uma espécie de indicador para que seja mensurada a qualidade de um processo produtivo circular. O primeiro ponto, segundo EEA (2016), se remete à redução do uso e aplicação de novos recursos naturais na cadeia produtiva. Essa medida visa reduzir a erosão de um ecossistema natural que é comumente causada por processos produtivos lineares. O segundo ponto deixa clara uma necessidade de se reduzir a quantidade de emissões poluentes tanto de forma direta como indireta. A implementação de medidas que se coloquem de forma a evitar perdas materiais e valor agregado dos produtos na cadeia circular, são postas como um terceiro ponto a ser averiguado. Ainda segundo EEA (2016) o terceiro e quarto ponto se amparam, respectivamente, nos procedimentos que visam aumentar a quantidade de materiais reciclados e reutilizados nos processos produtivos e nas práticas produtivas que aumentam o tempo de vida e a durabilidade dos itens produzidos.

Estudos recentes apontam a validade da adoção de um modelo circular. A adição de produtos já descartados no processo circular na indústria alimentar e química gerou uma redução na emissão de gases tóxicos gerados pelas empresas estudadas (Genovese et al., 2015). No mesmo sentido, Zhou et al. (2017), apontam vários benefícios para a indústria do metal caso sejam utilizados métodos circulares de produção como: realocação de matérias primas, utilização de fontes de energia renováveis, eficiência do sistema produtivo e reuso de material desperdiçado. Os benefícios obtidos foram uma redução nos custos ambientais 
externos e internos e benefícios econômicos para a empresa. Sokka et al. (2011) contribui para avaliar o quão valiosa é a simbiose industrial na indústria do papel. Lee e Thomsen (2014) colocam os ganhos oriundos no ciclo de vida do plástico por meio da Economia Circular. A água, quando utilizada de maneira circular, também trouxe benefícios para diversas empresas segundo Abu-Ghunmi \& Bino (2016), pelo fato de não ser desperdiçada e incorporada ao processo produtivo de algumas indústrias, ao mesmo tempo que, quando possível, era tratada para reutilização.

A Economia Circular atua como um sistema regenerativo, em que a entrada de novos materiais e recursos escassos, o vazamento de resíduos, as emissões de poluentes e o desperdício de energia são minimizados, de forma a atuar de maneira mais sustentável possível, pelo abrandamento, fechamento e estreitamento dos círculos energéticos e materiais. Isso pode ser alcançado pelas indústrias por meio de um contínuo processo produtivo pautado no eco-design, manutenção, reparação, reutilização, remanufatura, renovação e reciclagem dos produtos fabricados (Geissdoerfer et al., 2017).

Um modelo de economia circular não serve apenas como um propulsor autoconsciente da preservação ambiental adotado pela indústria, mas traz diversos benefícios financeiros e competitivos quando em comparação com industrias lineares, seja pela captação de fornecedores e consumidores também preocupados com a questão ambiental ou por um reprocessamento inteligente de suas ações aplicados a todo seu método produtivo (Srivastava, 2007). A aplicação da economia circular, pautada em um melhor design e em uma maior eficiência na utilização dos produtos, deve a partir de 2025, fazer com que os manufatureiros europeus economizem em torno de US\$630 bilhões por ano. No mesmo ano, poderá ser observado uma economia de 23\% em relação aos atuais gastos da indústria européia com insumos e aditivos manufatureiros. (Stahel, 2014). Para finalizar, a Tabela 1 apresenta a descrição conceitual das diferentes abordagens teóricas que deram origem a este estudo.

Tabela 1

Descrição conceitual

\begin{tabular}{|c|c|c|}
\hline Termos & Autor e Ano & Descrição do Conceito \\
\hline $\begin{array}{l}\text { Green Supply } \\
\text { Chain } \\
\text { Management }\end{array}$ & $\begin{array}{l}\text { Andic et al. } \\
(2012)\end{array}$ & $\begin{array}{l}\text { Minimizar e preferencialmente eliminar os efeitos negativos da cadeia } \\
\text { de suprimentos no meio ambiente. }\end{array}$ \\
\hline $\begin{array}{l}\text { SustainableSupply } \\
\text { Chain } \\
\text { Management }\end{array}$ & $\begin{array}{l}\text { Closs et al. } \\
(2011)\end{array}$ & $\begin{array}{l}\text { Reflexão da capacidade da empresa de planejar, mitigar, detectar, } \\
\text { responder e se recuperar de possíveis riscos globais. } \\
\text { Riscosenvolvendo } \text { marketing } \text { substancial e cadeia de }\end{array}$ \\
\hline
\end{tabular}




\begin{tabular}{|l|l|l|}
\hline & & $\begin{array}{l}\text { suprimentosconsiderações incluem desenvolvimento de produto, } \\
\text { seleção do canal, decisões de mercado, sourcing, complexidade da } \\
\text { manufatura, transporte, governo e regulação da indústria, } \\
\text { disponibilidade de recursos, gestão de talentos,plataformas } \\
\text { alternativas de energia e segurança }\end{array}$ \\
\hline Circular Economy & EMF (2013) & $\begin{array}{l}\text { A Economia Circular é restauradora e regenerativa por projeto e visa } \\
\text { manter produtos, componentes e materiaisna sua mais alta utilidade } \\
\text { e valor em todos os momentos, distinguindo entre ciclos técnicos e } \\
\text { biológicos. }\end{array}$ \\
\hline
\end{tabular}

Nota-se na Tabela1 que os 3 conceitos centrais da fundamentação teórica deste artigo são correlatos e objetivam de forma similar mitigar impactos ambientais, focam na eficiência no uso dos recursos naturais e contribuem na geração de impactos positivos para a sociedade a partir da operacionalização dessas práticas nas cadeias de produção, especialmente em nível de operações e produção.

\section{Metodologia}

Para o desenvolvimento desta pesquisa, se realizou uma investigação qualitativa, com enfoque descritivo. Foram mapeadas informações sobre as operações da cadeia de suprimentos sustentáveis no que se refere as repostas comerciais aos imperativos sustentáveis numa indústria madeireira do sul do Brasil;empresa esta que atua no mercado de madeireiro trabalhando com matéria prima reflorestada e remanejada. A Organização destaca que seus produtos são industrializados de forma ambientalmente correta e socialmente justa. Todo processo de beneficiamento usufrui de matérias-primas reflorestadas,renováveis, recicláveis, remanejadas e que são liberadas por órgãos competentes,. Portanto, torna-se um caso interessante para este estudo.

A estratégia de pesquisa escolhida foi o estudo de caso único. De acordo com Creswell (2007), estudo de caso é um procedimento de pesquisa que utiliza, geralmente, dados qualitativos coletados a partir de eventos reais, com o objetivo de explicar, explorar e/ou descrever fenômenos atuais inseridos em seu próprio contexto.

Com a utilização de diferentes fontes de evidência, como também do método de triangulação de dados, foram realizadas a análise documental, entrevistas semiestruturadas, e observação direta para facilitar a compreensão do caso investigado. Segundo Triviños (2011) a triangulação de dados tem como objetivo a amplitude na descrição e compreensão do foco de estudo, pois é impossível conceber a existência isolada de um fenômeno social. Além do mais, os dados empíricos foram cruzados com as principais abordagens e teorias 
apresentada pela literatura que destacam os conceitos essenciais, na definição de cadeias de suprimentos sustentáveis.

Foi realizada entrevista com os seguintes sujeitos: o presidente da organização, com o sócio diretor administrativo industrial, responsável pelas compras, gerente administrativo financeiro e responsável pelo sistema de logística e vendas, visando alcançar um entendimento satisfatório dos elos estabelecidos entre as operações da cadeia de suprimentos e os imperativos de sustentabilidade. As entrevistas foram realizadas entre os meses de junho e julho de 2017, os sujeitos selecionados são considerados sujeitos- chaves da organização. Para a coletas de dados durante as entrevistas foi utilizado gravador registrando as falas realizadas. Com relação aos entrevistados seguem alguns dados:

- Presidente da organização - entrevistado “A”, trabalha desde a fundação, tem 38 anos, possui ensino médio completo;

- Sócio Diretor Administrativo Industrial - entrevistado “B”, trabalha desde a fundação, tem 42 anos escolaridade ensino médio completo.

-Responsável comercial e de compras- entrevistado "C", trabalha há 11 meses na empresa, tem 28 anos, formado em sistemas de informação e pós-graduado em gestão comercial.

- Gerente Administrativo financeiro- entrevistado “E”, graduado em Economia e em Ciências Contábeis, pós-graduado em gestão comercial, 38 anos, trabalha na organização há mais de 6 anos.

- Responsáveis logísticas vendas - entrevistado “D”, graduação incompleta em Administração, possui 32 anos, trabalha há mais de 2 anos e meio na organização.

De posse dos dados das entrevistas, foram transcritos na íntegra e posteriormente se partiu para análise dos dados. A técnica de análise de dados seguiu algumas etapas proposta por Bardin (2004): pré-análise; exploração do material ou codificação; tratamento dos resultados e interpretação. O primeiro passo consiste em organizar e preparar os dados para analisar, são dados extraídos das entrevistas, considerado como uma fase de tratamento do material. Segunda etapa esteve associada a exploração do material, com o intuito de iniciar uma análise detalhada com objetivo de codificação dos dados e identificação das unidades de registro. Essa fase é considerada importante para esse estudo, pois visa permitir uma descrição exata das características pertinentes ao conteúdo expresso no texto. O terceiro momento é caracterizado pelo tratamento dos resultados, considerado como uma análise 
reflexiva e critica. Em sequência, o último passo é a apresentação dos dados, em que é realizada a interpretação e extração do significado dos dados obtidos nas etapas anteriores.

\section{Apresentação e Análise dos Dados}

A análise dos dados deu-se a partir das entrevistas e visa facilitar a compreensão da interpretação. Os pontos de conteúdo mais significativos foram por vezes narrados por meio de trechos dos discursos dos entrevistados. Suas falas foram fielmente reproduzidas e eventuais erros gramaticais foram mantidos para preservar a naturalidade dos relatos. Ressalta-se que questões éticas como: os nomes dos entrevistados bem como da organização pesquisada foram preservados. Logo os entrevistados foram tratados no decorrer do texto como entrevistas A, B, C, D e E e a empresa por XXX.

\section{Histórico Da Organização.}

A empresa estuda é a XXX Madeiras, uma madeireira que trabalha com industrialização, beneficiamentos e vendas de madeiras para todo o território brasileiro.No passado, segundo o presidente da organização se trabalhou com a exportação dos produtos industrializados, mas devido a conjuntura econômica brasileira, optou-se em trabalhar apenas no território nacional. Fundada em 15 de fevereiro de 2001, ainda como ramificação do grupo empresarial que atua no ramo madeireiro há 3 gerações, a organização estudada faz parte de um contexto familiar. Possui três sócios legíveis, sendo o pai já aposentado e os dois filhos que desempenham a função de presidente e diretor administrativo industrial. Para melhor atender a sua praça e distribuição, a organização faz uso de uma transportadora para otimizar o processo logístico, uma vez que sua localização é distante de seus principais clientes e fornecedores.

$\mathrm{Na}$ atual conjuntura, a empresa estudada é considera de médio porte, conforme dados do Banco Nacional de Desenvolvimento Econômico e Social - BNDES, poisobteve um faturamento acima de 3,6 milhões anuais. Atua em um pequeno município do interior do sudoesteParanaense, com aproximadamente 5 mil habitantes, empregando diretamente 130 colaboradores. Seus principais clientes são atacadistas. Também fornece mercadoria para clientes finais varejistas em pequena proporção. Entre os principais clientes destacam-se a empresa Tramontina, Vale do rio Doce e a empresa ferrovia do Brasil, responsável por toda 
a ferrovia de trens do território nacional, assim como empresas moveleiras da região sul do país.

A indústria XXX, processa pinheiro Araucária, Pinus, Eucalipto e outras madeiras, atendendo a demanda de seus clientes com todos os tipos de bitolas em madeira sem beneficiamento. Também presta serviços de colheita florestal, com ciclo completo que vai desde o processamento, carregamento e transporte do produto.

A empresa trabalha somente com matéria prima certificada de registro junto ao IBAMA, mediante emissão de licenças de operação e Certificado de registro SERFLOR, e apresentou um rígido controle de reaproveitamento de resíduos que são em sua totalidade utilizados para geração de energia ou doados para agropecuária para serem utilizados na cama de animais. E ainda segundo relado do entrevistado A, B e E, a entidade detém de uma vasta área de reflorestamento próprio.

\section{Papéis Das Operações Industriais Desempenham No Contexto Da Cadeia} De Suprimentos Sustentável.

Dentre os principais papéis das operações industriais desempenhando no contexto da cadeia de suprimentos sustentáveis, destacam o uso de matéria prima reflorestada e o manejo florestais, legalmente liberados pelos órgãos competentes, e a reciclagem, ou seja, reuso dos resíduos. Ao mencionar o reuso dos resíduos, se entendem o reaproveitamento do que de fato seria descartado no processo de produção, industrialização da matéria prima em produto beneficiado.

De acordo com as respostas dos respondentes se observou que objeto de estudo já faz uso de todo o descarte do seu processo de produção, uma vez que, para o beneficiamento da madeira, gera o que era chamado no passado de descarte como: a rasca da madeira e o excesso, tiras não alinhados com as bitolas padrões e a serragem , o que no passado ficava exposto ao meio ambiente e era queimado, ocasionando a poluição do ar e o ressecamento do solo no caso da serragem proveniente de arvores de eucaliptos quando acumulados em grandes montes. Conforme as respostas dos entrevistados há mais de 12 anos a organização se preocupa com o destino desses resíduos e os destinas de maneira circular.

No caso das sobras da madeira chamadas por ripas, tiras e a rasca a empresa destina para outra organização que faz uso como consumo no seu processo produtivo energético junto a frigoríficos locais, estimulando assim a redução de novas árvores cortadas para o 
mesmo destino. Também as sobras de madeira e ripasque não estão de acordo com as bitolas, medidas padronizadas é destinada para empresas fabricantes de cabos de vassoura, empresas que produzem cabos de pequenos objetos, exemplo espetos para churrasco e aos agricultores locais que usufruem para uso em canteiros de verduras e legumes.

Já a serragem, pelo fato de a região onde se encontra a sede da organização ser uma região agrícola e voltada para a produção de frangos de cortes, é utilizada pelo agronegócio com destino a forração do solo para abrigos de animais e aos agricultores familiares fazem uso na formação de canteiros de verduras e legumes.

Percebe-se que ao abordar o processo produtivo da organização em estudo há concordância com o que Ellen MacArthur Foundation (2013), mencionou ao se reportar na sua segunda categoria, elesenquadram os modelos de negócios que podem ser adotados para aprimorar uma cadeia produtiva de que a mesma impacte da menor forma possível a qualidade circular de seu processo produtivo. Os autores ainda salientam na sua última categoria a ideia de englobar diversos atores para atuarem de maneira colaborativa em prol de prevenir que itens produzidos venham a ser desperdiçados. Abaixo segue figura 1, como fluxograma simplificado da cadeia produtiva da madeireira.

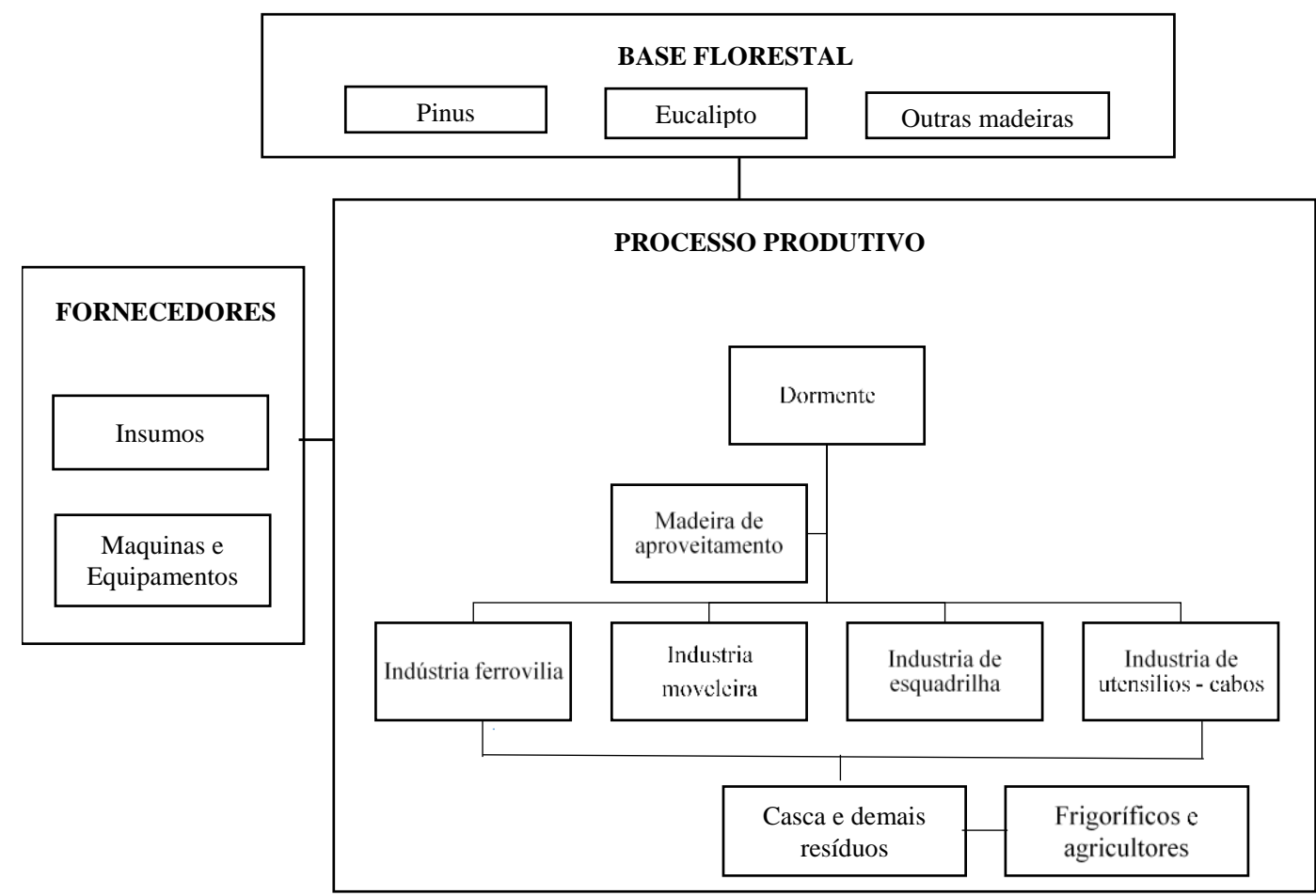

Figura 1. Fluxograma simplificado da cadeia produtiva

Fonte: os autores (2017). 
A Figura1, reporta o processo produtivo adotado pela madeira, relatando desde a entrada de matérias e demais insumos e o processo percorrido dentro de sua cadeia de suprimento para melhor explanar como ocorre as etapas das operações industriais.

Outro fator verificado adotado pela organização afim de melhorar o processo produtivo foi adoção de novas máquinas. No passado necessitava do uso excessivo contínuo de água para o processo de serrar a madeira, nos últimos cincos anos devido a exigências de seus parceiros clientes potenciais, a empresa adquiriu novas maquinas que o diminuiu o uso da água considerado em percentuais 95\%, conforme relato dos entrevistados. Recentemente a empresa também adotou o sistema de captação da água da chuva.

Verificou-se que em cerca do processo produtivo a organização no último ano fez aquisições de novas tecnologias para banhar, prolongar o ciclo de vida da madeira industrializada, o que no passado era realizado em processo de "céu aberto" sem os devidos cuidados ambientais e os devidos manejos, pois se utilizava em grande quantidade de produtos químicos e água. Com as novas tecnologias adotadas a madeira tratada passa por uma máquina, onde a água é reutilizada e o produto químico não é descartado no solo, exigindo menos exposição aos produtos químicos por parte de seus colaboradores. Quanto aos recipientes dos produtos químicos são recolhidos pela prefeitura local que emprega o devido destino.Essa afirmativa vai de encontro com a terceira categoria apresentada no estudo de Ellen MacArthur Foundation (2013),relacionam diretamente com os aprimoramentos tecnológicos que são desenvolvidos a fim de prolongar o ciclo de vida dos produtos produzidos.

A seguir segue relatos transcritos na integras dos entrevistados norteados acerca dos reuso dos resíduos nas operações produtivas.

Tabela 2

Relatos dos entrevistados

\section{Relato dos entrevistados acerca das operações industriais desempenhadas no contexto da} cadeia de suprimentos

Entrevista "A" $\quad[\ldots$. Nossa mercadoria é distribuída para várias empresas e tudo que não é utilizado e comprado pelos clientes, a gente faz o cavaco que é utilizado nas caldeiras. Nós aproveitamos 100\% do processo produtivo, nada vai fora. O material chega e em 5 ou 6 dias já não tem mais nada no pátio. Uma parte é transformado em cavaco, a outra é parte é destinada para os aviários.[...]Não utilizamos mais água nem serra fita. Hoje 80\% está tudo modernizado por questões de segurança. A gente aproveita até água da chuva aqui. Nada vai fora e ainda possuímos um sistema de captação de água da chuva e incrementamos o acumulado no processo. Todo o processo é circular e armazenado. 


\begin{tabular}{|c|c|}
\hline & $\begin{array}{l}\text { Depois de aplicado, tudo volta para o processo. Fazemos isso pela preocupação com o } \\
\text { meio ambiente. }\end{array}$ \\
\hline Entrevistado "B" & $\begin{array}{l}\text { Esse processo de tratamento tem um produto químico, a madeira entra dentro de um } \\
\text { processo com água a base de pressão e isso aí não é nada descartável [...] Nada é jogado } \\
\text { fora, o produto é aplicado na madeira, as próprias bombas devolvem de volta pras } \\
\text { próprias caixas e vai sempre repondo. O tratamento é fiscalizado. [...]Tudo é } \\
\text { reaproveitado, nada vai fora.[...]Na verdade a gente vende o farelo pra uma outra } \\
\text { empresa, eles usam pra fazer cama de aviário pra guardar os frangos e também os } \\
\text { colonos vem comprar para usar nos canteiros de verduras. O resto da nossa madeira, o } \\
\text { resto do dormente, a gente faz cavaco que vai pra [...] usado pra esquentar as caldeiras. } \\
\text { Então aqui na nossa empresa, nós não perdemos nada. }\end{array}$ \\
\hline Entrevistado "C" & $\begin{array}{l}\text { Busca o reflorestamento, dentro da empresa temos boas práticas, buscamos o } \\
\text { reaproveitamento máximo que podemos abater e desperdiçamos o menos possível. } \\
\text { Enquanto aqui dentro buscamos aproveitar ao máximo o material. Se sobrou, tentamos } \\
\text { sempre reaproveitar o material. O IPI que fornece para os funcionários por exemplo, são } \\
\text { todos aproveitados e não deixamos nenhum material tomar o destino errado. Damos a } \\
\text { destinação correta pro resíduos.[...]A gente procura fazer o reaproveitamento do } \\
\text { material pra não haver desperdício e pra não perder o material. Existe toda uma } \\
\text { preocupação com o Meio Ambiente. } \\
\text { As sobras podemos mandar para as outras empresas, a gente aproveita todo o material } \\
\text { porque o desperdício tem que aproveitar ao máximo. A gente faz tabua a gente faz a } \\
\text { dormente, madeira pro mercado de vaca e a sobra total gera cavaco e mandamos pras } \\
\text { empresas pra caldeira deles. Em torno de 99,9\% é reaproveitado. O farelo também é } \\
\text { vendido. Geralmente o pessoal que tem confinamento de gado busca bastante o farelo } \\
\text { pra confinar o gado. Pessoal vem buscando, parte é doado, parte é vendido }\end{array}$ \\
\hline $\begin{array}{l}\text { Entrevistado } \\
\text { "D” }\end{array}$ & $\begin{array}{l}\text { A preocupação com o descarte dos resíduos, destinação de material para biomassa, } \\
\text { outros produtos que vão para área dos frigoríficos. [..]Hoje nosso sistema de tratamento } \\
\text { já é automatizado para que ele seja reutilizado no produto, ou seja, dentro do sistema de } \\
\text { acondicionamento no tubo de tratamento, nós apenas reinserimos ele para que ele já } \\
\text { volte a ser reutilizado. Nós apenas fazemos um complemento com água e um adicional } \\
\text { de produto. Não há nenhuma espécie de descarte. As embalagens já são condicionantes } \\
\text { do fornecedor, então a troca de embalagem não é de nosso envolvimento. Cabe a ele fazer } \\
\text { a troca. Depois o material, quando é feito o ciclo de tratamento, ele vai banhar a madeira } \\
\text { sobre um ciclo de imersão e pressão e o que não foi absorvido, volta para o ciclo. A cadeia } \\
\text { tem uma característica de fechada e a preocupação ambiental com isso é adicionar a sua } \\
\text { planta alguns quesitos de segurança que evitem a contaminação caso haja algum } \\
\text { vazamento ou problema. As pessoas que fazem o manejo são designadas para essa tarefa, } \\
\text { fazem todo um treinamento especifico e recebem as orientações necessárias para o } \\
\text { manuseio. Os equipamentos utilizados são diferenciados, os uniformes são mais } \\
\text { reforçados, usa-se mascaras também. Dessa forma, são funcionários específicos. }\end{array}$ \\
\hline
\end{tabular}

Fonte: elaborado pelos autores (2017).

\section{Papéis Que A Organização Desempenha Enquanto Indústria}

\section{Processadora E Nas Suas Relações Inter-Organizacionais.}

\section{Dentre os principais papéis que organização estudada desempenha nas suas relações} inter-organizacionais com seus fornecedores e com os clientes na cadeia de recebimento de matéria prima e o repasse de produtos industrializado, está relacionada no quesito qualidade, melhor custo, benefício na compra de madeiras reflorestada e ou de manejo dentro dos quesitos legais, conforme orienta os órgãos ambientais. Portanto,a indústria atende demandas dos seus clientes e especifica diretrizes para os seus fornecedores. Esse 
relacionamento ocorre de maneira informal e é legitimado pela confiança recíproca entre as partes. Esse espírito de cooperação de fortalece ano e fortalece a cadeia de produção e, especialmente, legitima a indústria como coordenadora da cadeia.

Observou-se que pelo fato da empresa estar atuando há mais de três gerações no ramo do seu negócio, há uma preocupação com o meio ambiente e também para atender medidas legais, e a cobrança e auditoria de seus principais clientes pelo uso sustentável de seus insumos, bem como, à maneira do seu processo de industrialização. Outro relato abordado pelos entrevistados diz respeito ao setor madeireiro ser visto pela população em geral com um segmento que proporciona prejuízo e destruição ao meio ambiente, mas outrora hoje as maiores reservas reflorestadas e o manejos de grandes florestadas são influenciadas por empresas do setor que atuam legalmente dentro dos requisitos das leis. O próprio entrevistado "A", citou como exemplo o setor de pecuária e os danos causados ao meio ambiente.

Entrevistado A: Já fazem mais de 15 anos que estou na frente do negócio e só fazemos com madeira reflorestada e sempre incentivando o replantio e preservando o meio ambiente. O meu setor é o setor mal falado, o madeireiro que destrói a natureza, mas isso não é verdade, é o pessoal da pecuária, a gente só planta, colhe e planta, se pega uma região no MT ou no AM os madeireiros tem muito território, para eles não falta madeira. Como eles vão fazendo o manejo, eles vão cortando em linha reta e quando chegar no fim, até lá a madeira já cresceu de volta, isso é o manejo, enquanto a gente que trabalha com o gado é diferente, daí acaba caindo nas costas do madeireiro, ninguém enxerga algo assim.

Atentou-se que a organização realiza uma pesquisa quanto as medidas legais reflorestais alinhada junto a qualidade dos insumos na busca de novos fornecedores, e um dos quesitos exigidos é se de fato seus fornecedores estão trabalhando dentro do processo legal sustentável. Seus principais insumos é o eucalipto e o pinus, ambos provenientes de reflorestamento e raramente comercializa madeira exóticas, somente nos casos de manejos. A respeito dos fornecedores parceiros a cada aquisição é feito um processo de auditoria para se certificar se de fato estão dentro dos paramentos de qualidades exigidos e como procedeu o corte das arvores, se realmente são de manejos e ou reflorestas. 
Dentre os principais dificultadores apresentado pelos entrevistados estão em relação a alguns fornecedores se adequar as normas legais ambientais e mensurar a responsabilidade de fornecer produtos de áreas reflorestadas e ou de manejos devidamente autorizadas e o próprio destino, reuso de mercadorias que não comportam o padrão de qualidade requisitado. Conforme relato dos entrevistados no início houve restrições por parte de alguns fornecedores que no decorrer do tempo foram se habituando com as exigências e as auditorias que a empresa realiza.

Entrevistado D: A busca de matéria prima está toda focada em madeira de reflorestamento, quando buscamos fornecedores, fazemos todo o abate dos frutos e temos um contrato de retorno e quando essa parte replantada estiver pronta para ser utilizada, já temos uma manifestação no interesse de compra.

Entrevistado A: Temos problema com isso. Empresas que não trabalham e não se adequam a questão sustentável. Que não conseguem cumprir com as normas. Então cortamos os vínculos.

Entrevistado C: Podemos pegar a própria cortina por exemplo, existe uma empresa que fornece, mas quando tem algum estrago, eles tentam jogar fora e não reutilizam, então tem que ficar em cima.[...]é a dificuldade, ele não é fácil de se conseguir a madeira que vem do Mato grosso, tem que ficar de olho pra não mandar a madeira errada.[...]As vezes vem madeira podre, madeira que não era pra vir. Madeira fora da certificação, nós não aceitamos esse tipo de material.

Percebeu-se preocupação por parte da empresa não apenas com a qualidade dos insumos, mas também com a retirada legal das madeiras e as devidas quantidades fornecidas se de fato são todas de provenientes de medidas ambientais correta. Logo evidencia a inquietação da organização perante aos seus stakeholders e sua reputação a sociedade de modo geral.

Ao abordar sobre as exigências dos seus clientes com relação aquisição da matéria prima, processo de produção, qualidade e manejo sustentável, se atentou que a organização também é fiscalizada e cobrada sobre uso adequado de matérias primas, bem como a origem 
dessa matéria prima e os destinos de resíduos adequado, visto que recebem todo mês uma equipe de auditores de alguns de seus clientes potencias. Conforme menciona o entrevistado $\mathrm{B}$ “ [.. ] passamos por uma vistoria de todas as madeiras que a gente corta. Analisa-se que um clico de cobranças seja vinda da parte do governo seguido dos clientes e repassadas aos fornecedores.

Entrevistado A: Temos parcerias com empresas grandes que demonstram preocupação com a questão da segurança e do meio ambiente e eles ficam fiscalizando. Eles vieram para ficar por bastante tempo e pedem produtos de qualidade e corretamente ecológico.

Entrevistado C: [...]Fazemos de tudo para permanecer no mercado. Creio que o cliente valoriza, eles fazem visitas rotineiras para verificar e reconhecer o processo, chegar a situação.

Entrevistado D: Outro fator que serve como influenciador são os clientes. Somos reféns de um critério estabelecido pelas principais empresas. Nosso grupo de clientes tem uma cultura sustentável interna. São clientes que estão no topo de uma cultura sustentável, o que acaba nos motivando a fazer parte deste mercado competitivo.

Com relação a dificultadores em atender as exigências sustentáveis no processo, a empresa menciona que enfrentou apenas no começo da implantações dos reuso e descartes devidos no processo produtivo por parte da colaboração de alguns funcionário mais antigos que não estavam acostumados com a postura agora formalizada da organização, visto que era um desejo antigo da empresa em reestruturar todo processo de produção e os devidos descartes na economia circular, já que desprendia e cobrava de seus fornecedores matéria prima dentro dos quesitos legais e reflorestadas, e para receber clientes potencias e crescer no mercado houve essa necessidade que foi encarada com certa resistência por parte alguns colaboradores e fornecedores no início de adequação formalizada e na implantação com novas tecnologias.

A cerca da autoconsciente da preservação ambiental, Srivastava (2007) retrata os diversos benefícios financeiros e competitivos quando em comparação com industrias lineares, seja pela captação de fornecedores e consumidores também preocupados com a 
questão ambiental ou por um reprocessamento inteligente de suas ações aplicados a todo seu método produtivo.

\section{Papéis Desempenhados Pelo Ambiente Institucional.}

Observou que os sthakeholders do ambiente institucional possuem um papel fiscalizatório e gerador de pressão para a constante inclusão de melhorias contínuas nos processos, pois se tratam de clientes de média e grandes empresas, engajados com medidas sustentáveis, exigentes e instigam a empresa a inovar, a fazer inovações incrementais nos processos de produção, para atendê-los com produtos de qualidades e ecologicamente correto, caso da madeira beneficiada, ou reaproveitada com certificado dos órgãos SERFLOR (Sistema Estadual de Reposição Florestal Obrigatória) e do IBAMA(Instituto Brasileiro de Meio Ambiente e dos Recursos Naturais Renováveis), bem como o destino correto dos resíduos e o manuseio do processo produtivo. Ao abordar o manuseio do processo produtivo é imposição dos principais clientes potencias que a empresa obtenha medidas preventivas constantes de prevenção de acidentes, bem como: realização de treinamentos referente saúde e segurança no trabalho, prática de treinamentos sobre manuseio de resíduos perigosos, treinamentos sobre ergonomia no ambiente de trabalho, treinamentos sobre prevenção de acidentes no ambiente de trabalho e o uso e fiscalização adequado de equipamentos de segurança disponibilizados pela organização, conforme relato dos entrevistados abaixo.

Entrevistado D: Primeiro creio que é uma exigência a nível Federal e de Estado. Algumas regras são impostas e 50\% do resultado está envolto pelas regras que nos sãos impostas. Outra parte vem de encontro com o posicionamento frente a concorrência. Se não acompanharmos a concorrência, acabamos perdendo no quesito de competitividade.

Entrevistado C: [...] Segurança pro meio ambiente e treinamento para com os funcionários. O principal é manter e cuidar da segurança do meio ambiente. [...]. Os colaboradores cobramos muito e batemos muito na tecla da segurança. [...]. Nosso processo é bom aceito pelos clientes devido também as parcerias com a comunidade e com os clientes. Hoje 80\% está tudo modernizado por questões de segurança e exigência dos nossos maiores clientes...[...]. Temos parcerias com empresas grandes que demonstram preocupação com a questão da segurança e do meio ambiente e eles ficam fiscalizando.

Eles vieram para ficar por bastante tempo e pedem produtos de qualidade. 
Entrevistado A: Nesse documento consta a quantidade de metros cúbicos de madeira e tem que bater com os valores de estoque físico e com os dados do IBAMA. Então existe todo esse processo e o estoque tem que bater, porque o IBAMA pode vir aqui e conferir.

O governo por sua vez, cumpre o seu papel fiscalizatório e indutor de melhorias contínuas, principalmente associadas a proteção dos trabalhadores, seja via uso de equipamentos de proteção individual, exigências de horas de capacitação para operar máquinas perigosas e respeito as diretrizes trabalhistas, para que os trabalhadores possam ter uma vida digna.

No quesito sustentabilidade social, legalmente não possuem vínculos, mas se analisou de acordo com os relatos dos entrevistados que a empresa desprende de ajudas locais, para com famílias carentes do próprio município, por intermédio de doações de madeira para reforma e ou construção de suas casas, pois conforme relado do entrevistado A”[...] todo mundo tem direito de ter sua própria casa[...] e se hoje estamos bem graças a Deus, então a gente na medida do possível sempre procura ajudar as famílias pobres a construir sua casinha com doação das madeiras[...]. Devida a cultura religiosa dos proprietários, verificou que eles adotam em apoiar entidades locais como: a igreja católica, a APAE e também realizam doações mensais para o Hospital do Câncer.

Entrevistado A: Com certeza, nossa cidade tem 6 mil habitantes. Nós ajudamos muita gente, ajudamos o hospital do Câncer, eu não lembro agora mais. Mas a gente ajuda muito, ai tem muita coisa. A gente ajuda bastante gente. Com certeza estamos engajados, é muita coisa, bastante a gente ajuda, a gente faz festa na comunidade, a gente participa, a gente ajuda, a gente trabalha, pede para os funcionários participarem. Tem bastante coisa.

Em termos de responsabilidade compartilhada, logística reversa e gestão de resíduos os entrevistados não salientaram nenhum aspecto onde o governo tenha instigado ou pressionado a adoção de práticas específicas. As ações que são desenvolvidas pela empresa, são de interesse dos sócios e foram adotadas por livre iniciativa. Há a Política Nacional de Resíduos Sólidos, mas há muitas ingerências na adoção das premissas que essa lei prevê. Como não há fiscalização, cada gestor adota seu livre arbítrio para incorporar as práticas sustentáveis que na percepção dele são relevantes, são geradoras de vantagem competitiva e contribuem para a eficiência da cadeia de produção, conforme já destaca pelos entrevistados anteriormente. 
Os sindicatos, associações e entidades locais não possuem um papel representativo no ambiente institucional da organização pesquisada. Eventualmente, contribuem na oferta de capacitações, minicursos, palestras sobre temáticas que impactam positivamente no negócio da empresa.

\section{Plano Estratégico.}

Com base nos dados do relatório GRI (Global Reporting Initiative), foi proposto um plano estratégico de melhorias sustentáveis de acordo com as três dimensões relatadas no relatório, ou seja, dimensões Ambientais, Sociais e Econômicas. A seguir, o Tabela 3 apresenta as ações de melhoria praticas sugeridas, de acordo com as observações indiretas das entrevistas foi possível mensurar quem pode direcionar como fazer e quando.

Tabela 3

Práticas Sustentáveis Recomendadas para a Organização Pesquisa

\begin{tabular}{|c|c|c|c|c|c|}
\hline Dimensão & Práticas sugeridas & $\begin{array}{l}\text { Principais } \\
\text { autores }\end{array}$ & $\begin{array}{l}\text { Quem vai } \\
\text { fazer? }\end{array}$ & Como? & Quando? \\
\hline \multirow{15}{*}{$\begin{array}{l}\text { Práticas } \\
\text { ambientais }\end{array}$} & 1.Logística reversa & \multirow{15}{*}{$\begin{array}{c}\text { Philippi Jr } \\
\text { et al } \\
\text { (2002), } \\
\text { NBR 10004 } \\
\text { (2004) } \\
\text { Irigaray \& } \\
\text { Respino } \\
\text { (2012), } \\
\text { Roos \& } \\
\text { Becker } \\
\text { (2012), } \\
\text { GRI (2014) }\end{array}$} & \multirow{15}{*}{$\begin{array}{c}\text { Presidente, } \\
\text { mais gerente } \\
\text { da produção e } \\
\text { gerente } \\
\text { administrativo, } \\
\text { engenheiro } \\
\text { ambiental e } \\
\text { demais } \\
\text { funcionários } \\
\text { que } \\
\text { desempenha a } \\
\text { função dentro } \\
\text { do processo } \\
\text { produtivo, } \\
\text { bem como a } \\
\text { distribuição } \\
\text { dos produtos } \\
\text { até a coleta de } \\
\text { matéria prima. }\end{array}$} & \multirow{15}{*}{$\begin{array}{l}\text { Via orientações } \\
\text { para com os } \\
\text { funcionários } \\
\text { envolvidos } \\
\text { diretamente } \\
\text { nos processos, } \\
\text { com auxilio e } \\
\text { monitoramento } \\
\text { do engenheiro } \\
\text { ambiental. }\end{array}$} & \multirow{15}{*}{$\begin{array}{c}\text { Primeiro } \\
\text { semestre } \\
\text { de } 2018 \\
\text { até } \\
\text { segundo } \\
\text { semestre } \\
\text { de } 2019 .\end{array}$} \\
\hline & 2.Controle da poluição & & & & \\
\hline & 3. Eco-inovação & & & & \\
\hline & $\begin{array}{l}\text { 4. Sistema de Gestão } \\
\text { ambiental }\end{array}$ & & & & \\
\hline & 5. Energias limpas & & & & \\
\hline & 6. Eco-design & & & & \\
\hline & 7. Consumo sustentável & & & & \\
\hline & $\begin{array}{l}\text { 8. Resíduos zero } \\
\text { (reciclagem interna) }\end{array}$ & & & & \\
\hline & $\begin{array}{l}\text { 9. Prevenção e controle de } \\
\text { poluição integrados }\end{array}$ & & & & \\
\hline & 10. Química verde & & & & \\
\hline & $\begin{array}{l}\text { 11. Auditorias de } \\
\text { processos internos }\end{array}$ & & & & \\
\hline & $\begin{array}{l}\text { 12. Auditoria para com } \\
\text { fornecedores }\end{array}$ & & & & \\
\hline & $\begin{array}{l}\text { 13. Auditorias ambientais } \\
\text { nos processos produtivos } \\
\text { e de gerenciamento dos } \\
\text { efluentes e resíduos }\end{array}$ & & & & \\
\hline & $\begin{array}{l}\text { 14. Uso de águas } \\
\text { superficiais nos processos }\end{array}$ & & & & \\
\hline & $\begin{array}{l}\text { 15.Manejo } \\
\text { ambientalmente saudável } \\
\text { dos resíduos perigosos }\end{array}$ & & & & \\
\hline
\end{tabular}




\begin{tabular}{|c|c|c|c|c|c|}
\hline & $\begin{array}{l}\text { 16. Tecnologias de } \\
\text { processo que reduzem } \\
\text { consumo de energia }\end{array}$ & & & & \\
\hline & $\begin{array}{l}\text { 17. Uso de combustíveis } \\
\text { oriundos de fontes } \\
\text { renováveis }\end{array}$ & & & & \\
\hline & $\begin{array}{l}\text { 18. Avaliação do ciclo de } \\
\text { vida dos produtos }\end{array}$ & & & & \\
\hline & $\begin{array}{l}\text { 19.Acordo ambientais } \\
\text { voluntários }\end{array}$ & & & & \\
\hline \multirow{10}{*}{$\begin{array}{l}\text { Práticas } \\
\text { Sociais }\end{array}$} & 1.Responsabilidade social & \multirow{10}{*}{$\begin{array}{l}\text { Philippi Jr } \\
\text { et al } \\
\text { (2002), } \\
\text { Irigaray \& } \\
\text { Respino } \\
\text { (2012), } \\
\text { Roos \& } \\
\text { Becker } \\
\text { (2012), } \\
\text { GRI (2014) }\end{array}$} & \multirow{10}{*}{$\begin{array}{l}\text { Presidente da } \\
\text { organização, } \\
\text { mais } \\
\text { responsável da } \\
\text { área de } \\
\text { Recursos } \\
\text { Humanos e } \\
\text { Gerente } \\
\text { Administrativo } \\
\text { e assessoria } \\
\text { jurídica. }\end{array}$} & \multirow{10}{*}{$\begin{array}{l}\text { Adequando a } \\
\text { gestão de } \\
\text { Recursos } \\
\text { Humana, } \\
\text { juntamente } \\
\text { com o técnico } \\
\text { de segurança } \\
\text { do trabalho, } \\
\text { elaborando } \\
\text { regimento } \\
\text { interno com } \\
\text { princípios, } \\
\text { deveres e } \\
\text { politicas legais } \\
\text { da organização; } \\
\text { concedendo } \\
\text { benéficos para } \\
\text { os } \\
\text { colaboradores } \\
\text { com projeto de } \\
\text { dedução no } \\
\text { imposto de } \\
\text { renda, uma vez } \\
\text { que a } \\
\text { organização se } \\
\text { encontra no } \\
\text { regime } \\
\text { tributário lucro } \\
\text { real }\end{array}$} & \multirow{10}{*}{$\begin{array}{l}\text { Segundo } \\
\text { semestre } \\
\text { de } 2018\end{array}$} \\
\hline & $\begin{array}{l}\text { 2. Práticas Trabalhistas } \\
\text { baseadas em normas } \\
\text { universais } \\
\text { internacionalmente } \\
\text { reconhecidas }\end{array}$ & & & & \\
\hline & $\begin{array}{l}\text { 3. Contratações } \quad \text { de } \\
\text { empregados } \\
\text { discriminando cotas }\end{array}$ & & & & \\
\hline & $\begin{array}{l}\text { 4. Concessão de benefícios } \\
\text { regularmente } \\
\text { empregados de tempo } \\
\text { integral da organização }\end{array}$ & & & & \\
\hline & $\begin{array}{l}\text { 5. Monitoramento e } \\
\text { registro dos tipos de } \\
\text { lesões, (a taxa de lesões, a } \\
\text { taxa de } \\
\text { ocupacionais, doenças } \\
\text { perdidos, a taxa de } \\
\text { absenteísmo) e número de } \\
\text { óbitos relacionados ao } \\
\text { trabalho para o total de } \\
\text { trabalhadores (ou seja, } \\
\text { empregados próprios e } \\
\text { terceirizados) }\end{array}$ & & & & \\
\hline & 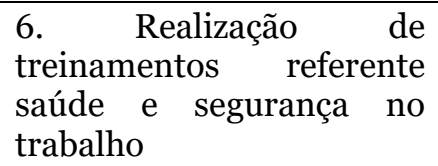 & & & & \\
\hline & $\begin{array}{lr}\text { 7.Realização } & \text { de } \\
\text { treinamentos } & \text { sobre } \\
\text { manuseio de } & \text { resíduos } \\
\text { perigosos } & \end{array}$ & & & & \\
\hline & $\begin{array}{l}8 . \quad \text { Realização } r \\
\text { treinamentos } \\
\text { ergonomia no ambiente de } \\
\text { trabalho }\end{array}$ & & & & \\
\hline & $\begin{array}{l}\text { 9. Realização } \quad \text { de } \\
\text { treinamentos } \\
\text { prevenção de acidentes no } \\
\text { ambiente de trabalho }\end{array}$ & & & & \\
\hline & $\begin{array}{lr}10 . \quad \text { Realização } & \text { de } \\
\text { treinamento } & \text { sobre } \\
\text { aspectos dos direitos } \\
\text { humanos relevantes para } \\
\text { as operações } \\
\text { organização }\end{array}$ & & & & \\
\hline
\end{tabular}




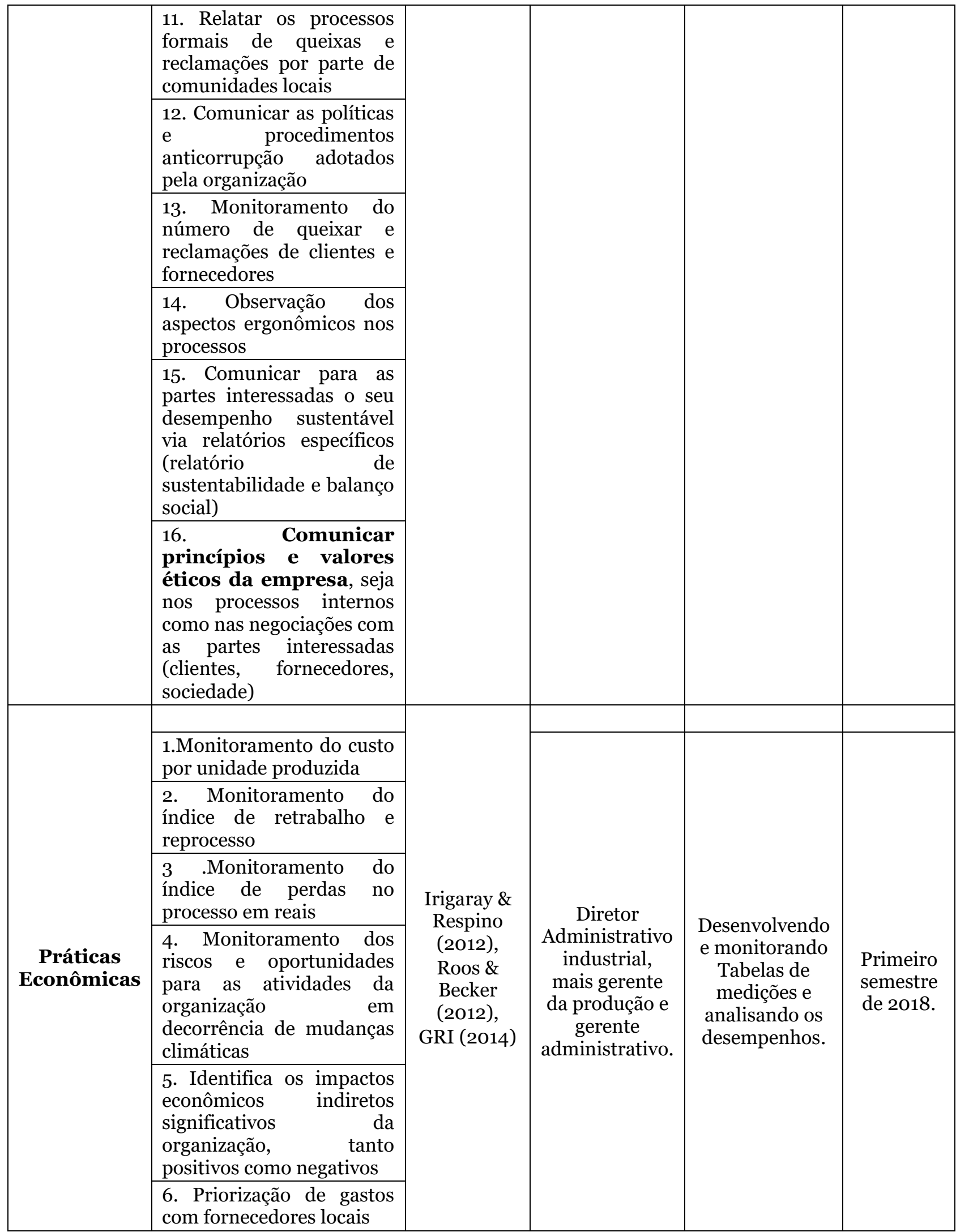

Fonte: os autores (2017). 
Segundo a literatura, a saber, Piquetti (2018) e Sehnem, Lukas e Marques (2015), são estas as práticas que contribuem para gerar cadeias produtivas sustentáveis, que sejam competitivas, inovadoras e eficientes. A inclusão dessas práticas na organização, de acordo com as prioridades dos gestores, pode ser importante para gerar valor para a empresa na captação de novos clientes. Principalmente se for associado a criação de indicadores de mensuração, de monitoramento e acompanhamento do estágio de adoção da prática e o impacto financeiro para a empresa.

\section{Conclusão}

Esta pesquisa teve como objetivo analisar o papel que as operações da cadeia de suprimentos sustentável podem desempenhar nas organizações numa perspectiva que direcione para a circularidade de recursos. Evidências da pesquisa, tanto da literatura como do caso empírico, sinalizam que a incorporação de práticas sustentáveis é uma estratégia adotada pelas organizações no setor industrial para angariar vantagem competitiva, aumentar a eficiência dos processos e reduzir custos. E o setor de produção é o ambiente em que essas práticas são incorporadas de forma mais acentuada, pois há oportunidades para reduzir custos, desperdícios, aumentar a circularidade de recursos, gerenciar desperdícios e introduzir inovações sustentáveis.

Constatou-se que o papel que as operações industriais desempenham no contexto das cadeias de suprimentos sustentáveis é essencial e relevante. Pois suas operações responsáveis na geração de poluentes e resíduos são tratadas de maneira que minimizem o passivo ambiental que a empresa gera, por meio da circulação de todos os resíduos dentro da cadeia produtiva, aproveitado por outros agentes como os frigoríficos e os agricultores locais. Os relatos que são produzidos a partir das práticas operacionalizadas são utilizados para comunicação com os públicos relevantes, e portanto, se tornam instrumental de marketing da organização pesquisada.

A organização apresentou um importante papel no pilar ambiental, via engajamento de múltiplos stakeholders por meio de cumprimentos legais ambientais e a conscientização em prol da sustentabilidade ambiental. Já nas diretrizes social relacionado a normas e leis trabalhista dos direitos humanos, manuseios e treinamentos de operações de agentes tóxicos e maquinas, conclui que organização age pensando dentro dos quesitos legais, 
impulsionadas não somente por órgãos governamentais, mais principalmente instigada pelos clientes potenciais.

A empresa pesquisada desenvolve várias práticas de sustentabilidade, entre elas o uso adequado e legalizado de matéria prima reflorestada, reservas ambientais próprias, desperdício de resíduos zero, por intermédio da circulação servindo de insumos para outras cadeias de produção, sistema de captação de água e destino correto de embalagens tóxicas. Seus recursos humanos são capacitados para operarem as máquinas, são contratados seguindo a legislação trabalhista e recebem equipamentos de proteção individual para exercerem as suas funções. Na dimensão econômica, os salários pagos aos trabalhadores atendem o salário base de cada função vigente na região de localização da empresa. Todos os direitos trabalhistas são cumpridos integralmente. Portanto, há um compromisso em manter os funcionários satisfeitos, para que permaneçam na empresa. O custo da demissão, de novas contratações e o treinamento são elevados e portanto, manter o funcionário é a melhor opção.

No quesito sustentabilidade social relacionada a inclusão social, voluntariado, criação de valores e condutas que valorizam a diversidade e as diferenças, mobilização da sociedade via ações de conscientização em prol da sustentabilidade, a empresa contribui espontaneamente para a comunidade local, famílias carentes igrejas APAE, e o hospital do câncer em prol de um mundo mais humano. A cerca da sustentabilidade social averiguo a preocupação dos gestores em realizar campanhas incentivadoras para os colaboradores acerca da responsabilidade sustentável ambiental na preocupação de manter a natureza e meio ambiente agradável para as futuras gerações, por meio de auditorias zero desperdícios.

Acerca do ambiente institucional (governos, sindicatos, entidades representativas dos setores industriais e consumidores) e seu papel no âmbito da responsabilidade compartilhada de produtos, a implementação de sistemas de logística reversa e a gestão de resíduos envolvendo as cidades, as empresas, distribuidoras e importadoras têm cumprido, na percepção dos pesquisados um papel fiscalizatório e de pressão para incorporação de novas práticas sustentáveis. Não atender as exigências de clientes significa que eles não retornam. Portanto afins de agentes ativos financeiros é prezado as diretrizes que os clientes exigem.

O plano estratégico sustentável foi proposto de acordo as três dimensões do relatório GRI, pois se constatou o interesse dos gestores em tornar a organização mais competitiva e sustentável perante ao perfil traçado na parceria com futuros clientes, uma vez, que a 
empresa almeja uma maior participação de mercado conforme seu planejamento estratégico. Dessa forma, a principal contribuição teórica deste estudo consiste na validação das premissas de cadeia de suprimentos sustentáveis no âmbito de uma indústria madeireira. Mostra o alinhamento das diretrizes teóricas com as evidências empíricas, sinalizando que as práticas mapeadas dão conta de uma ênfase na dimensão ambiental para mitigação de impactos negativos gerados pela empresa e para dar notoriedade as ações/metas e objetivos estabelecidos pela empresa, especialmente para atender as pressões dos seus stakeholders relevantes. No quesito contribuição prática, serve de case para benchmarking das boas práticas por outras organizações do setor, para a evidenciação de quão comprometida com a sustentabilidade se encontra a organização pesquisada, e especialmente, como sinalizador de oportunidades para o avanço da sustentabilidade, descritas no plano de melhoria contínua proposto.

Dentre as principais limitações deste esta relacionadas a amostragem entrevistada, pois não se conseguiu entrevistar o engenheiro ambiental o maior agente e engajador das implantações de normas sustentáveis, e os principais fornecedores e clientes da organização, visto que a empresa não autorizou as entrevistas com seus parceiros externos. Limitando certas reflexões acerca das pratica sustentáveis com o engajamento dos demais agentes da sua cadeia de suprimentos.

Recomenda-se para futuros estudos ampliar a análise para outras empresas do mesmo segmento consideradas de médio a grande porte engajada juntamente com analise junto a cadeia de suprimentos. Outra possibilidade de estudo é replicar esta pesquisa a outras empresas do segmento por meio de um survey, para analisar o desempenho no contexto sustentável no contexto da cadeia de suprimentos. 


\section{Referências}

Abu-Ghunmi, D., Abu-Ghunmi, L., Kayal B., \& Bino, A. (2016). Circular economy and the opportunity cost of not 'closing the loop'of water industry: the case of Jordan. J. Clean Prod., in press.

Andic, E., Yurt, O., \& Baltacioglu, T. (2012). Green supply chains: efforts and potential applications for the Turkish market. Resources, Conservation and Recycling, 58, 50-68.

Associação Brasileira de Normas Técnicas. NBR 10.oo4: Resíduos Sólidos: Classificação: atividades técnicas. Recuperado de http://www.abnt.org.br.

Bardin, L. (2004). Análise de conteúdo. (3. ed.). Lisboa: Edições 70.

Carter, C. R., \& Rogers, D. S. (2008). A framework of sustainable supply chain management: moving toward new theory. International Journal Of Physical Distribution \& Logistics Management, 38(5), 360-387.

Closs, D.J., Speier, C., \& Meacham, N. (2011). Sustainability to support end-to-end value chains: the role of supply chain management. Journal of the Academy of Marketing Science, 39 (1), $101 \mathrm{e} 116$

Creswell, J. W., \& Clark, V. L. P. (2007). Designing and conducting mixed methods research.

Di Maio, F., Rem, C., Valdé, P., \& Polder, M. (2017). Measuring resource efficiency and circular economy: a market value approach. Resource, conservation and recycling, 122. 163-171.

Elia, V., Gnoni, M. G., \& Tornese, F. (2006). Measuring circular economy strategies through index methods: A critical analysis. Journal of Cleaner Production, 142(20), Part 4, 27412751.

Ellen MacArthur Foundation. (2013). Towards the Circular Economy: Economic and business rationale for an accelerated transition.

Ellen MacArthur, E. (2013). Towards the Circular Economy: Opportunities for the consumer goods sector. Ellen MacArthur Foundation. London. 
European Environmental Agency (2016). Circular economy in Europe: Developing the knowledge base (2).

Geissdoerfer, M., Savaget, P., Bocken, N., \& Hultink, E.J. (2017). The Circular Economy: A new sustainability paradigm? Journal of Cleaner Production, 143, 757-768.

Genovese, A., Acquaye, A. A., Figueroa, A., \&Koh, S. L. (2017). Sustainable supply chain management and the transition towards a circular economy: Evidence and some applications. Omega, 66, 344-357.

Global Reporting Initiative (2014). Diretrizes para Relatórios de Sustentabilidade. Versão 4.o. Recuperado de http://www.globalreporting.org/ NR/rdonlyres/4855C490-A8724934-9EoB-8C2502622576/5288/DiretrizesG3.pdf.

Irigaray, H. A., \& Respino, R. M. (2012). Estudo de caso comparativo entre o modelo de sustentabilidade adotado pela ANTF e o modelo GRI. Revista de Administração da UNIMEP, 10(3).

Jabbour, A., \& Souza, C. (2015). Oportunidades e desafios para lidar com as barreiras à adoção de práticas de Green Supply Chain Management: Guidelines à luz de um estudo de múltiplos casos no Brasil. Gestão \& Produção, 22(2), 295-310.

Lee, J., Pedersen, A. B., \& Thomsen, M. (2014). The influence of resource strategies on childhood phthalate exposure - the role of REACH in a zero waste society. Environment International, 73:312-322.

Mehdi, S. A. Sustainable Supply Chain Management in Pithoragarh: Prospects of Rural Tourism. The Iup Journal of Supply Chain Management, 14(1), 16-31. Recuperado de https://search.proquest.com/openview/2d4cbo4eoo96a69b192f6fd16a91e952/1?pqorigsite $=$ gscholar\&cbl $=2030007$.

Meixell, M. J., \& Luoma, P. (2015). Stakeholder pressure in sustainable supply chain management: A systematic review. International Journal of Physical Distribution \& Logistics Management, 45(1/2), 69-89. Recuperado de http://dx.doi.org/10.1108/ijpdlm-05-2013-0155. 
Nascimento, E. P. (2012). Trajetória da sustentabilidade: do ambiental ao social, do social ao econômico. Estudos Avançados, 26(74), 51-64.

Nascimento, L., Lemos, Â., \& Mello, M. (2008). Gestão Sócio-Ambiental Estratégica. Porto Alegre: Bookman.

Oelze, N. (2017). Sustainable supply chain management implementation-enablers and barriers in the textile industry. Sustainability, 9(8),1435

Pagell, M., \& Wu, Z. (2009). Building a More Complete Theory of Sustainable Supply Chain Management using case studies of 10 exemplars. Journal of Supply Chain Management, $45(2), 37-56$.

Piquetti, A. (2018). Interfaces existentes entre os indicadores do Programa Propriedade Rural Sustentável e as diretrizes do Global Reporting Initiative (GRI). (Dissertação de Mestrado Profissional em Administração). Chapecó.

Rogers, Dale S., \& Tibben-Lembke, Ronald S. (1999). Going Backwards: Reverse Logistics Trends and Practices. Pittsburgh, PA: RLEC Press.

Ritzén, S., \& Gunilla Ö. S. (2017). Barriers to the Circular Economy-Integration of Perspectives and Domains. Procedia CIRP, 64, 7-12.

Sehnem, S., Lukas, M. C., \& Marques, P. D. (2015) Elaboração e aplicação dos indicadores de sustentabilidade em pequenas e médias empresas. NAVUS - Revista de Gestão e Tecnologia, 5(3), 22-41.

Sehnem, S., \& Oliveira, G. P. (2016). Gestão da Cadeia de Suprimentos Verde: uma Análise da Relação Fornecedor e Agroindústria de uma Empresa do Sul do Brasil. Brazilian Business Review. 13(6), 163-196.

Sokka, L., Pakarinen, S., \& Melanen, M. (2011). Industrial symbiosis contributing to more sustainable energy use-an example from the forest industry in Kymenlaakso. Finland. $J$ Clean Prod. 19(4):285-293.

Srivastava, S. K. (2007). Green Supply Chain Management: A State-of-the-Art Literature Review. International Journal of Management Reviews, 9(1), 53-80. 
Stahel, W. R. (2016). Circular economy: a new relationship with our goods and materials would save resources and energy and create local jobs. Nature, 531(7595), 435-439.

Triviños, A. N. S. (2011). Introdução à pesquisa em ciências sociais: a pesquisa qualitativa em educação. São Paulo: Atlas, 2006.

World Economic Forum (2014). Towards the Circular Economy: Accelerating the scale up across global supply chains. Recuperado de http://www3.weforum.org/docs/WEF_ENV_TowardsCircularEconomy_Report_2014. pdf.

Zhou, Z., Zhao, W., Chen, X., \& Zeng, H. (2017). MFCA Extension from a Circular Economy Perspective: Model Modifications and Case Study. Journal of Cleaner Production, 149, $110-125$. 